\title{
Expression Analysis of DNA Methyltransferases among Children Infected with Mycobacterium tuberculosis
}

\author{
Gayathri Pandurangan ${ }^{1}$, Noyal Mariya Joseph², Mahadevan Subramaniyan ${ }^{1 *}$ \\ ${ }^{I}$ Department of Paediatrics, Jawaharlal Institute of Postgraduate Medical Education and \\ Research (JIPMER), Puducherry, India \\ ${ }^{2}$ Department of Microbiology, Jawaharlal Institute of Postgraduate Medical Education and \\ Research (JIPMER), Puducherry, India \\ *Corresponding author
}

\begin{tabular}{l} 
Ke y w o r d s \\
DNA Methylation, \\
DNA \\
Methyltransferases, \\
DNMT in TB, \\
Paediatric TB\& \\
Epigenetics in TB \\
\hline $\begin{array}{l}\text { Article Info } \\
\text { Accepted: } \\
\text { 04 November } 2020 \\
\text { Available Online: } \\
\text { 10 December } 2020\end{array}$ \\
\hline
\end{tabular}

Keywords

DNA Methylation, DNA

DNMT in TB,

Paediatric TB\&

Epigenetics in TB

Article Info

Accepted:

Available Online:

10 December 2020
DNA Methylation plays a significant role in the prompt functioning of the immune system during the pathogenesis of Mycobacterium tuberculosis among paediatric population. Methylation is catalysed and regulated by DNA Methyltransferases (DNMTs). DNMT1, DNMT3A and DNMT3B are the essential DNMTs involved in the active transfer of Methyl group to the DNA. Thus, the upregulated DNMTs could pave way for hypermethylation of salient immune molecules and thereby transcriptionally inactivating the immune molecules involved in eliciting primary immune response. This study was aimed to determine the expression levels of DNA Methyltransferases namely DNMT1, DNMT3A and DNMT3B among children infected with $M . t b$ and compared with healthy children as controls. A total of 60 cases and 60 controls were recruited to estimate and compare the expression levels of DNMTs. The expression of the mRNAs coding DNMT1, DNMT3A and DNMT3B were analysed by Real-time Quantitative PCR assay. Comparatively among children infected with $M . t b$, the expression of DNMT1, DNMT3A and DNMT3B were upregulated [DNMT1 - 0.72(IQR 0.27-1.0); DNMT3A- 0.52(IQR 0.42-.76)\& DNMT3B-0.85(IQR 0.74-0.97)] while healthy controls showed downregulated pattern of expression[DNMT1-0.24 (IQR 0.20-.49); DNMT3A- 0.22 (IQR 0.14-.43)\& DNMT3B- 0.37(IQR0.30-0.74)]. Thus, the upregulated pattern of DNMTs expression among cases would have assisted pathogenesis by deregulating the transcriptional machinery of host immune system through DNA methylation based Epigenetic modulation.

\section{Introduction}

DNA methylation is the widely studied mechanism in epigenetics, which was first identified in DNA of calf thymus by Hotchkiss (Bestor, 2000). DNA methylation plays a significant role in several biological processes like gene expression, organization of chromatin, chromosomal integrity, silencing of harmful sequences, genomic imprinting, homologous recombination(Jones and Wolffe, 1999; Migeon, 1994; Tate and Bird, 1993). On the other hand,the role of DNA methylation gains attention in the 
pathogenesis of many infectious diseases as the phenomenon has a wide role in prompt functioning of the immune system and alteration of somatic cells, thus taking part in the aetiology of several diseases. DNA methylation prevents the activation of exogenous DNA in animals and plants, which restricts transgene expression that can lead to tumorigenesis (Cameron et al., 1999). DNA methylation and the associated histone changes play vital role in transcriptional silencing and hetero-chromatin modelling, which alter the gene expression (Colot and Rossignol, 1999). It also maintains cellular activities and alterations in the methylation signature leading to autoimmune diseases and cancer (Richardson, 2002).

DNA methylation is the covalent addition ofa methyl group $(\mathrm{CH} 3)$ to the 5th carbon of a cytosine base that is followed by guanine base $(\mathrm{CpG})$,which is catalyzed by the enzymes, DNA methyltransferases (DNMTs). The methyl group isdonated by $\mathrm{S}$-adenosyl methionine (SAM), which is converted to Sadenosyl homocysteine (SAH). This will then be converted back to SAM through a folic acid and cobalmine dependant pathway. CpG methylation is a carrier of epigenetic signature that plays a vital role in modelling and functioning of the chromatin. DNA methylation acts in two ways either it can inhibit gene expression directly or it increases the chance of mutation in an affected genemutation in an affected gene (Wajed et al., 2001).

DNA methyltransferases are the enzymes that bind to the DNA and cause the covalent modification of cytosine base for the transfer of methyl group from SAM to C5 of cytosine. Four DNMTs that are distinct in structure and function have been identified till date: DNMT1, DNMT2, DNMT3A and DNMT3B (Okano et al., 1999; Xie and He, 1999; Yoder, 1998). Based on the biological functions,
DNMTs can be classified into two groups:

De novo methyltransferases - DNMT3A and DNMT3B

Maintenance methyltransferases - DNMT1 and DNMT2

The first eukaryotic DNA methyltransferase to be purified and cloned was DNMT1. Loss of DNMT1 leads to deletion of methylation signature found to be a causative risk factor in cancers (Mizuno et al., 2001). DNMT3 family (DNMT3A and DNMT3B) introduces the denovo $\mathrm{CpG}$ methylation pattern in early embryonic stage, during organism development, and tumorigenesis while DNMT1 maintains the methylation signature during DNA replication. DNMT3 family includes three methyltransferases: DNMT3A, DNMT3B and DNMT3L. DNMT3L expression was found ingerm cells lacking methyltransferase activity but acts as regulator of other DNMT3 proteins (Liang et al., 2002). DNMT3A \&3B also play significant role in methylation maintenance by re-establishing methyl groups that are lost because of DNMT1 (Hu et al., 2008). In several congenital malformations and other diseases, DNMT3 was found to be defective (Tao et al., 2008).

Similar to DNMT3L, DNMT2 also lacks DNA methylation activity but recently it was shown that DNMT2 catalyses tRNA methylation (Goll et al., 2006).

Numerous studies on cancer epigenetics have documented that increase in expression of DNMT1, DNMT3A and DNMT3B are associated with disease onset and disease severity (Cannuyer et al., 2015; Girault and Bieche, 2003; Subramaniam et al., 2014; Zhang and $\mathrm{Xu}$, 2017). Particularly up regulated DNMT1 is a well-defined characteristic in most of the cancers and 
several results further speculated the association of the upregulated DNMTI in gastric cancer and colorectal cancer tissues (Etoh et al., 2004; Kanai et al., 2001; Toyota et al., 1999). Uropathogenic E. coli (UPEC) infection has showed upregulated expression of DNMT1 in human uroepithelial cells. This upregulated DNMT1 had facilitated susceptibility in the host by epigenetically downregulating CDKN2A (p16INK4A) pathway (Tolg et al., 2011; Tolg and Bägli, 2012). Madeddu et al, described in a study that in patients with chronic Hepatitis B virus infection the duration of viral therapy has been influenced by the over expression of DNMT1 as it deregulates pathways of cyclin dependent kinase-CDK4/6-pRb-E2F1 and p38mAPK in acquiring immunity (Madeddu et al., 2017). Another study by $\mathrm{Fu}$ et al, proved that hepatitis $\mathrm{B}$ virus $\mathrm{X}$ protein enhances upregulation of DNA Methyltransferases 3A and 3B (Fu et al., 2016). In addition, studies on hepato carcinoma cell lines infected with HCV showed that DNMTs were highly manipulated by the organism to thrive in the host and when the DNMTs were down regulated, severely impaired $\mathrm{HCV}$ infection at sub- genomic level were noticed. Interestingly it had also been proved that there was a significant reduction in $\mathrm{HCV}$ infection with the introduction of DNMT inhibitors. In addition, reports of many studies on epigenetic reprogramming of host immune genes in bacterial and viral pathogenesis were evident to state the crucial role played by DNMTs in deregulating pathways involved in acquiring immunity (Al Akeel, 2013; Paschos and Allday, 2010). Thus, the study was aimed to determine the association of DNMTs expression and M.tb disease pathogenesis in Paediatric Tuberculosis.

\section{Materials and Methods}

A total of 60 children with active TB disease (Cases) and 60 healthy children (Controls) were recruited for the study. Children aged between $>2 \leq 14$ yrs of both genders were involved in the study. The study children were matched with age and gender between the cases and controls. Participants were explained with the purpose of the study and written informed consent/ascent was obtained. Venous blood samples were collected from all the cases and controls.

\section{Extraction of Total RNA}

An equal volume of TRIzol reagent and whole blood was added to a tube (TRIzol $500 \mu \mathrm{L}+$ Blood $500 \mu \mathrm{L}$ ) and mixed vigorously. Subsequently, $1.5 \mathrm{~mL}$ of chloroform was added to the tube and mixed vigorously for 15 sec and kept at room temperature for 5 mins. Then the mixture was centrifuged at 10,000 rpm for $15 \mathrm{~min}$ at $4^{\circ} \mathrm{C}$.

The colourless upper transparent layer was then transferred to a fresh tube and $0.5 \mathrm{~mL}$ of isopropanol was added and gently the content was mixed. The mixture was incubated at room temperature for 5 mins and centrifuged at $10,000 \mathrm{rpm}$ for $10 \mathrm{~min}$ at $4^{\circ} \mathrm{C}$.

The supernatant was discarded and $1 \mathrm{~mL}$ of $70 \%$ ethanol was added to the pellet to wash the cellular components/debris. Following the addition of ethanol, the tubes were centrifuged at $14,000 \mathrm{rpm}$ for $5 \mathrm{mins}$ at $4^{\circ} \mathrm{C}$.The supernatant was discarded and the washing step was repeated again. The tubes were centrifuged at $14,000 \mathrm{rpm}$ for $5 \mathrm{mins}$ at $4^{\circ} \mathrm{C}$. The supernatant was removed and the tubes were allowed to dry in a dry bath to get rid of the residual alcohol.

Finally, RNA containing pellet was suspended in 30-50 $\mu \mathrm{L}$ of RNase-free water (Clontech Laboratories, Inc, CA, USA) in a water bath at $55^{\circ} \mathrm{C}$ for $5 \mathrm{~min}$. The suspended RNA was readily used for further analyses. 
DNasel Treatment - Removal of Genomic DNA

Extracted total RNA was subjected to removalof genomic DNA contamination to aid effective conversion of RNA to cDNA.

The procedure was carried out in a RNase free tube as follows,

$\begin{array}{ll}\text { RNA } & -1 \mu \mathrm{g} \\ \text { 10X Reaction Buffer with } \mathrm{Mgcl}_{2} & -1 \mu \mathrm{L} \\ \text { DNase I, RNase-free } & -1 \mu \mathrm{L} \\ \text { Water, nuclease-free } & -1 \mathrm{Ml}\end{array}$

The tube was mixed gently and incubated at $37^{\circ} \mathrm{C}$ for $30 \mathrm{~min}$.

$1 \mu \mathrm{L} 50 \mathrm{mM}$ EDTA was added to the content to stop the reaction and followed by incubation at $65^{\circ} \mathrm{C}$ for $10 \mathrm{~min}$.

The prepared RNA was used as a template for reverse transcriptase procedure.

\section{Quality and quantity analysis of Total RNA}

The extracted RNA was further checked for its quality to carry out downstream analyses. The purity and concentration of the extracted RNA were measured in NanoDrop spectrophotometer (ThermoFisher Scientific, MA, USA). The absorbance at 260/280 ratio ranging from 1.7-2.0 was considered as good quality RNA. All the extracted RNA samples were subjected to quality analysis before further experiments

\section{Complimentary DNA (cDNA) - First Strand cDNA Synthesis}

Complementary DNA (cDNA) was synthesized from one microgram $(1 \mu \mathrm{g})$ of total RNA by using the RevertAid H Minus First Strand cDNA synthesis kit (ThermoFisher Scientific, USA).

All the kit components were thawed into room temperature and mixed by a brief centrifugation and placed in ice throughout the procedure.

As inthe order listed below the kit components were added sequentially in a sterile, nucleasefree tube.

$\begin{array}{lc}\text { Template RNA (total RNA) } & -2-3 \mu \mathrm{L}(1 \mu \mathrm{g}) \\ \text { Primer - oligo (dT) })_{18} \text { Primer } & -1 \mu \mathrm{L} \\ \text { Water, nuclease-free (to make-up) } & -8-9 \mu \mathrm{L} \\ \text { 5X Reaction Buffer } & -4 \mu \mathrm{L} \\ \text { RiboLock RNase Inhibitor }(20 \mathrm{U} / \mu \mathrm{L})-1 \mu \mathrm{L} \\ 10 \mathrm{mM} \text { dNTP } & -2 \mu \mathrm{L} \\ \text { RevertAid H Minus M-MuLV Reverse } & -1 \mu \mathrm{L} \\ \text { Transcriptase } & (200 \mathrm{U} / \mu \mathrm{L}) \\ & -20 \mu \mathrm{L}\end{array}$

The content was mixed gently and briefly centrifuged. Then the tubes were incubated for $60 \mathrm{~min}$ at $42^{\circ} \mathrm{C}$.

Finally, to terminate the reaction, the tubes were incubated at $70^{\circ} \mathrm{C}$ for $5 \mathrm{~min}$.

The converted cDNA was stored at $-40^{\circ} \mathrm{C}$ for further qRT-PCR analysis.

\section{qRT-PCR analysis of candidate genes}

The expression profile of DNA methyltransferase genes was analyzed in a total of $60 \mathrm{~TB}$ cases and 60 healthy children. The amplification of both housekeeping and target genes from cDNA was performed in a total of $20 \mu \mathrm{L}$ of reaction volume.

The preparation of qRT-PCR reaction mixture as follows,

$\begin{array}{lc}\text { Template cDNA (1:10 dilution) } & -2 \mu \mathrm{L} \\ \text { Gene-specific Primer (200 nM) } & \\ \text { Forward Primer } & 0.4 \mu \mathrm{L} \\ \text { Reverse Primer } & -0.4 \mu \mathrm{L} \\ \text { Takara SYBR master mix (TB Green Premix Ex } \\ \text { Taq II Tli } \\ \text { RNase H Plus, Takara Bio Inc., Japan) }-10 \mu \mathrm{L} \\ \text { Water, nuclease-free (Clontech Laboratories, Inc, } \\ \text { CA, USA) } & -7.2 \mu \mathrm{L} \\ \text { Total volume } & -20 \mu \mathrm{L}\end{array}$

The qRT-PCR amplification reaction was performed on CFX96 Real-Time PCR 
Detection System (Bio-Rad, USA) with the cycling conditions as follows,

$\begin{array}{ll}\text { Initial denaturation } & -95^{\circ} \mathrm{C} \text { for } 30 \mathrm{sec} \\ \text { Denaturation } & -95^{\circ} \mathrm{C} \text { for } 5 \mathrm{sec} \\ \text { Annealing } & -60^{\circ} \mathrm{C} \text { for } 30 \mathrm{sec}\end{array}$

Repeat $2^{\text {nd }}$ and $3^{\text {rd }}$ step for 40 cycles.

Beta-2 microglobulin ( $\beta 2 M)$ was used as a housekeeping gene to normalize the $\mathrm{Ct}$ (cycle threshold) value in both cases and control samples.
Melt-curve analysis was performed to ensure accurate amplification and to avoid unspecific amplification; the products were melted from $60^{\circ} \mathrm{C}$ to $90^{\circ} \mathrm{C}$ at a rise of $0.2^{\circ} \mathrm{C} / \mathrm{min}$. The melting temperature $(\mathrm{Tm})$ of the amplicons were observed using fluorescence intensity ($\mathrm{dF} / \mathrm{dT}$ ) in Real-Time PCR detection System. PCR assays were performed in duplicates, and the reproducibility of the SYBR green assay was assessed by running control samples independently. To determine the relative quantification of a target gene and reference gene, the qRT-PCR data were analyzed in comparison to healthy controls using the comparative $2^{-\Delta \Delta C T}$ method.

Table.1 Primer for Housekeeping Gene

\begin{tabular}{|c|c|c|c|}
\hline S.No & Gene Symbol & qRT-PCR primers $\left(\mathbf{5}^{\prime} \mathbf{-} \mathbf{3}^{\prime}\right)$ & Tm \\
\hline \multirow{2}{*}{1} & \multirow{2}{*}{$\mathrm{M}$} & ATGAGTATGCCTGCCGTGTG & 6 \\
\cline { 3 - 3 } & & CCAAATGCGGCATCTTCAAAC & \\
\hline
\end{tabular}

Table.2 Primers of DNA Methyltransferases

\begin{tabular}{|c|c|c|c|}
\hline S.No & Gene Symbol & qRT-PCR primers $\left(5^{\prime}-3^{\prime}\right)$ & Tm \\
\hline \multirow[t]{2}{*}{1} & \multirow[t]{2}{*}{ DNMT1 } & ACCAAGCAGGCATCTCTGAC & \multirow[t]{2}{*}{56} \\
\hline & & ACCAGCTTCAGCAGGATGTT & \\
\hline \multirow[t]{2}{*}{2} & \multirow[t]{2}{*}{ DNMT3A } & GGGACGTCCGCAGCGTCACAC & \multirow[t]{2}{*}{60} \\
\hline & & CAGGGTTGGACTCGAGAAATCGC & \\
\hline \multirow[t]{2}{*}{3} & \multirow[t]{2}{*}{ DNMT3B } & AGCAGTACCCCCTACGCCCG & \multirow[t]{2}{*}{64} \\
\hline & & CTGGACCCACCGCATGCCAG & \\
\hline
\end{tabular}

\section{Results and Discussion}

Expression pattern of DNA methyltransferases (DNMTs) among cases and controls

DNA methyltransferases genes DNMT1, DNMT3A and DNMT 3B expression pattern was studied among all the cases and controls. The median difference in expression these genes were compared and a significant difference between cases and controls were observed. The results showed upregulation of
DNMT1, DNMT3A and DNMT 3B genes in children with active TB disease.

Comparatively among children infected with $M . t b$, the expression of DNMT1, DNMT3A and DNMT3B were upregulated [DNMT1 0.72(IQR 0.27-1.0); DNMT3A- 0.52(IQR 0.42-.76) \& DNMT3B-0.85(IQR 0.74-0.97)] while healthy controls showed downregulated pattern of expression [DNMT1-0.24 (IQR 0.20-.49); DNMT3A- 0.22 (IQR 0.14-.43)\& DNMT3B- 0.37(IQR0.30-0.74)] (Fig. 1). 
Table.3 Expression analysis of DNMTs among cases and controls

\begin{tabular}{|l|l|l|l|} 
Gene & Cases & Control & P value \\
\hline DNMT1 & $0.72(\mathrm{IQR} 0.27-1.0)$ & $0.24(\mathrm{IQR} 0.20-.49)$ & 0.0001 \\
\hline DNMT3A & $0.52(\mathrm{IQR} 0.42-.76)$ & $0.22(\mathrm{IQR} 0.14-.43)$ & 0.0001 \\
\hline DNMT3B & $0.85(\mathrm{IQR}$ 0.74-0.97) & $0.37(\mathrm{IQR} 0.30-0.74)$ & 0.0001 \\
\hline
\end{tabular}

Fig.1 Box plot showing expression ratio of DNMTs among cases and controls

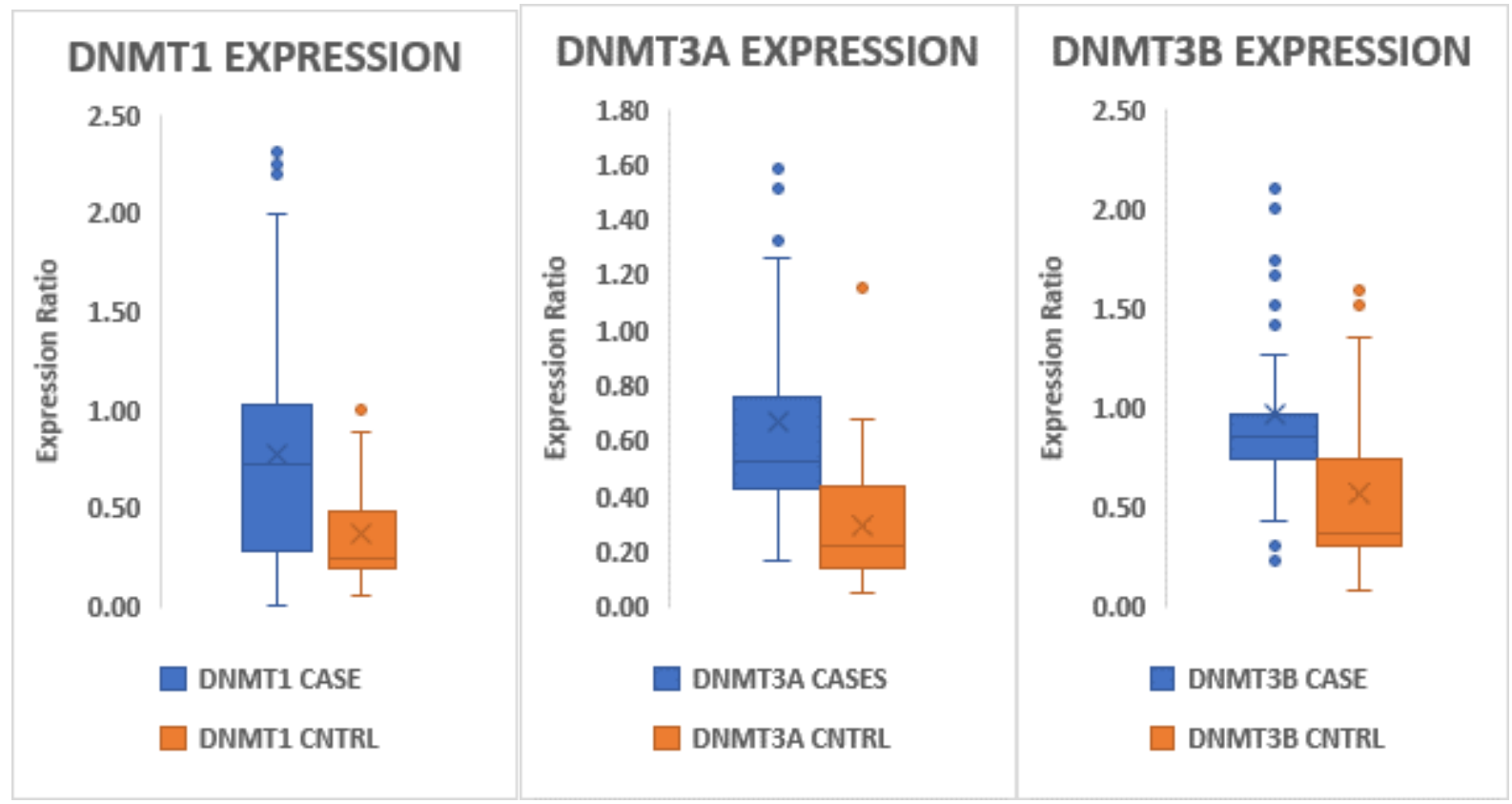

DNA methyltransferases are the enzymes that catalyses the transfer of methyl group to specific $\mathrm{CpG}$ sites in DNA. Predominantly this process was carried out by DNMT1 gene while DNMT3A and DNMT3B are known to carry out de nova methylation. Upregulation of these genes is associated with the developmental abnormalities, immunodeficiency, onset of cancers etc. The expression of DNMTs in children infected with TB could affect the pattern of methylation of salient immune genes which would in turn affect the expression of these genes and eventually impact the prognosis of the disease. DNA methyltransferases DNMT1, DNMT3A, and DNMT3B holding a pivotal role in establishing DNA methylation was observed to be significantly upregulated in cases than healthy controls. From this finding it can be inferred that there might be an association between the upregulated DNMTs and aberrant methylation pattern of immune genesso as to aid progression of disease in cases.

Infection induced deregulation of DNMTs were recorded from many study findings to state that the molecules secreted by the organism as a part of thriving mechanism or the organism per se could act as a potential epimutagen to enhance pathogenesis. Uropathogenic E.coli (UPEC) infection has 
showed upregulated expression of DNMT1inhuman uroepithelial cells. This upregulated DNMT1 had facilitated susceptibility in the host by epigenetically downregulating CDKN2A (p16INK4A) pathway (Tolg et al., 2011; Tolg and Bägli, 2012). Among patients with chronic Hepatitis $B$ virus infection the duration of viral therapy has been influenced by the overexpression of DNMT1 as it deregulates pathways of cyclin dependent kinase-CDK4/6-pRb-E2F1 and p38mAPK in acquiring immunity(Madeddu et $a l ., 2017)$. Fu et al, proved that hepatitis B virus $\mathrm{X}$ protein enhances upregulation of DNA Methyltransferases 3A and 3B(Fu et al., 2016). In addition, studies on hepato carcinoma cell lines infected with $\mathrm{HCV}$ showed that DNMTs were highly manipulated by the organism to thrive in the host and when the DNMTs were downregulated, severely impaired HCV infection at sub- genomic level were noticed. Interestingly it had also been proved that there was a significant reduction in $\mathrm{HCV}$ infection with the introduction of DNMT inhibitors (Chen et al., 2013).These studies further support our finding that upregulated DNMTs might have played crucial role in establishing infection.

The LANA protein expressed in Kaposi's sarcoma-associated herpesvirus was shown to interact with cellular DNMTS and facilitated de novo DNA methylation in a study on KSHV infected cell lines. This study further sets example of de novo DNMT activity recruited by viral protein to establish promotor specific epigenetic DNA modification(Shamay et al., 2006).Human papillomavirus (Protein-E7) and adenovirus (protein-EIA) infection showed a direct association in stimulating DNMTs upregulation during pathogenesis(Burgers et $a l ., 2007)$. In addition, reports of many studies on epigenetic reprogramming of host immune genes in bacterial and viral pathogenesis were evident to state the crucial role played by
DNMTs in deregulating pathways involved in acquiring immunity (Al Akeel, 2013; Paschos and Allday, 2010) (Table 1-3).

The present study findings with upregulated pattern of DNMTs (DNMTI, DNMT3A and DNMT3B) in children infected with tuberculosis match with the existing evidences. As quoted earlier upregulated DNMTs might have been promoted by microbial components to aid pathogenesis and to induce immunosuppressives in the host. The enhanced expression level of the members in DNMTs (DNMT1, DNMT3A and DNMT3B) is therefore inferred that it might be responsible for promotor specific epigenetic DNA modification and overall increased methylation level in the immune genes. Thus, functional pathways are further required to be explored to trace the involvement of DNMTs recruitment in hampering/ deregulating the immune molecules in the progression of active disease may lead to new preventative strategies in controlling TB.

\section{References}

Al Akeel, R. (2013). Role of epigenetic reprogramming of host genes in bacterial pathogenesis. Saudi Journal of Biological Sciences, 20(4), 305-309. https://doi.org/10.1016/j.sjbs.2013.05.0 03

Bestor TH. The DNA methyltransferases of mammals. Human Molecular Genetics [Internet]. 2000 Oct 1 [cited 2020 Jul 10];9(16):2395-402. Available from: https://academic.oup.com/hmg/articlelookup/doi/10.1093/hmg/9.16.2395

Burgers, W. A., Blanchon, L., Pradhan, S., Launoit, Y. de, Kouzarides, T., and Fuks, F. (2007). Viral oncoproteins target the DNA methyltransferases. Oncogene, 26(11), 1650-1655. https://doi.org/10.1038/sj.onc.1209950

Cameron EE, Bachman KE, Myöhänen S, 
Herman JG, Baylin SB. Synergy of demethylation and histone deacetylase inhibition in the re-expression of genes silenced in cancer. Nat Genet [Internet]. 1999 Jan [cited 2020 Jul 10];21(1):1037.

Cannuyer J, Van Tongelen A, Loriot A, De Smet C. A gene expression signature identifying transient DNMT1 depletion as a causal factor of cancer-germline gene activation in melanoma. Clin Epigenet [Internet]. 2015 Dec [cited 2020 Nov 9];7(1):114. Available from: https://clinicalepigeneticsjournal.biome dcentral.com/articles/10.1186/s13148015-0147-4Chen, C., Pan, D., Deng, A.M., Huang, F., Sun, B.-L., and Yang, R.-G. (2013). DNA methyltransferases 1 and $3 \mathrm{~B}$ are required for hepatitis $\mathrm{C}$ virus infection in cell culture. Virology, 441(1), $57-65$. https://doi.org/10.1016/j.virol.2013.03.0 05

Colot V, Rossignol JL. Eukaryotic DNA methylation as an evolutionary device. Bioessays. 1999 May;21(5):402-11. doi: 10.1002/(SICI)1521-1878(199905) 21:5<402::AID-BIES7>3.0.CO;2-B. Erratum in: Bioessays 1999 Aug; 21(8): 712. Erratum in: Bioessays 1999 Oct; 21(10): following 893. PMID: 10376011.

Etoh, T., Kanai, Y., Ushijima, S., Nakagawa, T., Nakanishi, Y., Sasako, M., Kitano, S., and Hirohashi, S. (2004). Increased DNA Methyltransferase 1 (DNMT1) Protein Expression Correlates Significantly with Poorer Tumor Differentiation and Frequent DNA Hypermethylation of Multiple $\mathrm{CpG}$ Islands in Gastric Cancers. The American Journal of Pathology, 164(2), 689-699.

https://doi.org/10.1016/S0002-

9440(10)63156-2

Fu, X., Song, X., Li, Y., Tan, D., and Liu, G.
(2016). Hepatitis B virus $X$ protein upregulates DNA methyltransferase $3 \mathrm{~A} / 3 \mathrm{~B}$ and enhances SOCS-1CpG island methylation. Molecular Medicine Reports, 13(1), 301-308. https://doi.org/10.3892/mmr.2015.4545

Girault I, Tozlu S, Lidereau R, Bièche I. Expression analysis of DNA methyltransferases $1,3 \mathrm{~A}$, and $3 \mathrm{~B}$ in sporadic breast carcinomas. Clin Cancer Res. 2003 Oct 1; 9(12):4415-22. PMID: 14555514Goll, M. G., Kirpekar, F., Maggert, K. A., Yoder, J. A., Hsieh, C.L., Zhang, X., Golic, K. G., Jacobsen, S. E., and Bestor, T. H. (2006). Methylation of tRNA ${ }^{\text {Asp }}$ by the DNA Methyltransferase Homolog Dnmt2. Science, 311(5759), 395-398. https://doi.org/10.1126/science.1120976 Hu, Y.-G., Hirasawa, R., Hu, J.-L., Hata, K., Li, C.-L., Jin, Y., Chen, T., Li, E., Rigolet, M., Viegas-Péquignot, E., Sasaki, H., and Xu, G.-L. (2008). Regulation of DNA methylation activity through Dnmt3L promoter methylation by Dnmt3 enzymes in embryonic development. Human Molecular Genetics, 17(17), 2654-2664 https://doi.org/10.1093/hmg/ddn165

Jones, P. L., and Wolffe, A. P. (1999). Relationships between chromatin organization and DNA methylation in determining gene expression. Seminars in Cancer Biology, 9(5), 339-347. https://doi.org/10.1006/scbi.1999.0134

Kanai Y, Ushijima S, Kondo Y, Nakanishi Y, Hirohashi S. DNA methyltransferase expression and DNA methylation of CPG islands and peri-centromeric satellite regions in human colorectal and stomach cancers. Int J Cancer. 2001 Jan 15;91(2):205-12. doi: 10.1002/10970215(200002)9999:9999<::aidijc1040>3.0.co;2-2. PMID: 11146446.

Liang, G., Chan, M. F., Tomigahara, Y., Tsai, Y. C., Gonzales, F. A., Li, E., Laird, P. 
W., and Jones, P. A. (2002). Cooperativity between DNA Methyltransferases in the Maintenance Methylation of Repetitive Elements. Molecular and Cellular Biology, 22(2), 480-491.

https://doi.org/10.1128/MCB.22.2.480491.2002

Madeddu, G., Ortu, S., Garrucciu, G., Maida, I., Melis, M., Muredda, A. A., Mura, M. S., and Babudieri, S. (2017). DNMT1 modulation in chronic hepatitis B patients and hypothetic influence on mitochondrial DNA methylation status during long-term nucleo(t)side analogs therapy. Journal of Medical Virology, 89(7), 1208-1214. https://doi.org/10.1002/jmv.24742

Migeon,BR X-chromosome inactivation: molecular mechanisms and genetic consequences, Trends in Genetics, Volume 10, Issue 7,1994,Pages 230-235,ISSN 0168 9525,https://doi.org/10.1016/01689525(94)90169-4

Mizuno, S., Chijiwa, T., Okamura, T., Akashi, K., Fukumaki, Y., Niho, Y., and Sasaki, H. (2001). Expression of DNA methyltransferases DNMT1,3A, and $3 \mathrm{~B}$ in normal hematopoiesis and in acute and chronic myelogenous leukemia. Blood, 97(5), 1172-1179. https://doi.org/10.1182/blood.V97.5.117 2

Okano, M., Bell, D. W., Haber, D. A., and Li, E. (1999). DNA Methyltransferases Dnmt3a and Dnmt3b Are Essential for De Novo Methylation and Mammalian Development. Cell, 99(3), 247-257. https://doi.org/10.1016/S00928674(00)81656-6

Paschos, K., and Allday, M. J. (2010). Epigenetic reprogramming of host genes in viral and microbial pathogenesis. Trends in Microbiology, 18(10), 439-447. https://doi.org/10.1016/j.tim.2010.07.00 3

Richardson, B. C. (2002). Role of DNA Methylation in the Regulation of Cell Function: Autoimmunity, Aging and Cancer. The Journal of Nutrition, 132(8), 2401S-2405S. https://doi.org/10.1093/jn/132.8.2401S

Shamay, M., Krithivas, A., Zhang, J., and Hayward, S. D. (2006). Recruitment of the de novo DNA methyltransferase Dnmt3a by Kaposi's sarcomaassociated herpesvirus LANA. Proceedings of the National Academy of Sciences, 103(39), 14554-14559. https://doi.org/10.1073/pnas.060446910 3

Subramaniam, D., Thombre, R., Dhar, A., and Anant, S. (2014). DNA Methyltransferases: A Novel Target for Prevention and Therapy. Frontiers in Oncology, 4. https://doi.org/10.3389/fonc.2014.00080 Tao, J., Yang, M., Chen, Z., Huang, Y., Zhao, Q., Xu, J., Ren, H., Zhao, H., Chen, Z., Ren, Q., and Yang, R. (2008). Decreased DNA Methyltransferase 3A and 3B mRNA Expression in Peripheral Blood Mononuclear Cells and Increased Plasma SAH Concentration in Adult Patients with Idiopathic Thrombocytopenic Purpura. Journal of Clinical Immunology, 28(5), 432-439. https://doi.org/10.1007/s10875-0089223-2

Tate, P. H., and Bird, A. P. (1993). Effects of DNA methylation on DNA-binding proteins and gene expression. Current Opinion in Genetics and Development, $3(2)$, 226-231. https://doi.org/10.1016/0959437X(93)90027-M

Tolg, C., and Bägli, D. J. (2012). Uropathogenic Escherichia coli infection: Potential importance of epigenetics. Epigenomics, 4(2), 229- 
235. https://doi.org/10.2217/epi.12.5

Tolg, C., Sabha, N., Cortese, R., Panchal, T., Ahsan, A., Soliman, A., Aitken, K. J., Petronis, A., and Bägli, D. J. (2011). Uropathogenic E. coli infection provokes epigenetic downregulation of CDKN2A (p16INK4A) in uroepithelial cells. Laboratory Investigation, 91(6), 825-836.

https://doi.org/10.1038/labinvest.2010.1 97

Toyota M, Ahuja N, Ohe-Toyota M, Herman JG, Baylin SB, Issa JP. CpG island methylator phenotype in colorectal cancer. Proc Natl Acad Sci U S A. 1999 Jul 20;96(15):8681-6. doi: 10.1073/pnas.96.15.8681. PMID: 10411935; PMCID: PMC17576..

Wajed, S. A., Laird, P. W., and DeMeester, T. R. (2001). DNA Methylation: An Alternative Pathway to Cancer: Annals of Surgery, 234(1), 10-20. https://doi.org/10.1097/00000658200107000-00003

Xie S, Wang Z, Okano M, Nogami M, Li Y, He WW, Okumura K, Li E. Cloning, expression and chromosome locations of the human DNMT3 gene family. Gene. 1999 Aug 5;236(1):87-95. doi: 10.1016/s0378-1119(99)00252-8.

PMID: 10433969.Yoder, J. (1998). A candidate mammalian DNA methyltransferase related to pmt1p of fission yeast. Human Molecular Genetics, $\quad 7(2), \quad$ 279-284. https://doi.org/10.1093/hmg/7.2.279

Zhang, W., and Xu, J. (2017). DNA methyltransferases and their roles in tumorigenesis. Biomarker Research, 5(1), 1. https://doi.org/10.1186/s40364017-0081-z

\section{How to cite this article:}

Gayathri Pandurangan, Noyal Mariya Joseph, Mahadevan Subramaniyan. 2020. Expression Analysis of DNA Methyltransferases among Children Infected with Mycobacterium tuberculosis. Int.J.Curr.Microbiol.App.Sci. 9(12): 256-265.

doi: https://doi.org/10.20546/ijcmas.2020.912.034 